\title{
12 Philosophical Foundations and the Role of Counseling in the Ethics of Informed Consent
}

\subsection{Introduction}

The postwar outcry against Nazi medical experiments conducted on human subjects led to heated debates regarding the ethical principles of informed consent. In the late fifties, medical and research institutes came to acknowledge the patient's right to decide on subjecting his/her body to high-risk treatments and experiments. However, informed consent and the ethical principles underlying its use and interpretation in clinical cases were given due consideration only much later. In 1972, Jay Katz released a monumental work dedicated to the history of informed consent and the medical process of seeking patients' informed consent (Katz 1972). Although Katz tried to rationally reconstruct the history of informed consent, his steadfast mistrust in the way in which medical and research institutions obtained patients' consent was either criticized or ignored by the medical community. A decade later, in 1982, Martin S. Pernik published a study entitled "The Patient's Role in Medical Decision Making: A Social History of Informed Consent in Medical Therapy” (Pernick 1982). Pernik's study was well received due to his liberal approach and extremely generous definition of the concept of informed consent. Finally, in 1986, Ruth R. Faden and Tom L. Beauchamp put out A History and Theory of Informed Consent (Faden and Beauchamp 1986), which was considered an attempt to find an adequate definition for the concept of informed consent and to offer a systematic analysis of its ethical principles.

These important studies became methodological guidelines due to their thorough and spectacular reviews of the thorny issues related to informed consent in the medical practice $^{1}$; nonetheless, they failed to provide a clear-cut account of either informed consent or the ethical principles underlying it. Moreover, after reviewing the recent literature, we arrived at the conclusion that in the past years, there has hardly been any substantial contribution to a better understanding of informed consent, besides refining or updating existing definitions by resorting to comparative analyses and various case studies ${ }^{2}$.

This study argues that divergent approaches to informed consent are, to a large extent, determined by previously established philosophical presuppositions. We

1 Grzegorz Mazur, for instance, describes them as foundational or paradigmatic theories, which truly established the main methodological guidelines in the area of informed consent $(2012,1-8)$.

2 Refer, for instance, Manson and O’Neill (2007) and Hammond (2016). 
try to reveal these presuppositions by analyzing the most prominent definitions of informed consent and its underlying ethical principles. In the final section, we put forward an original proposal in an attempt to iron out existing differences, and we suggest the addition of a new intermediary step in the process of obtaining informed consent, one that could lead to a more robust ethical foundation for this sensible and difficult process.

\subsection{Informed consent as an expression of liberty}

What is informed consent? If we accept the supposition made by Faden and Beauchamp, according to which the informed consent doctrine originates in the care to protect and facilitate clinical patients' and subjects' autonomy and free choice $(1986,235)$, we need to define consent by resorting to terms such as autonomy or, to be more specific, autonomous action. In other words, informed consent is the free choice of an agent (patient/subject) to accept a specific treatment or surgical intervention.

This brief definition contains three implicit premises: first, that the respective action is meant to improve the patient's health; secondly, that this is going to be a potentially dangerous intervention that may lead to an improvement of the patient's health, but which may also involve risks; thirdly, that there is no other intervention capable of producing the same effects without adjacent risks for the patient's health.

Let us suppose we are dealing with a patient facing an end-stage disease. Doctors recommend an experimental treatment with a good track record in tackling the respective disease, but which may lead to health problems given the patient's condition. Under the circumstances, doctors will ask for the patient's consent or, if the patient is not mentally competent or unable to provide consent, they will seek the consent of the patient's nearest relative.

When the patient is asked to give his/her consent, he/she is provided with all relevant data - both benefits and risks - and procedures concerning the medical intervention. In this scenario, seeking the patient's consent means actually passing the responsibility for the proposed treatment onto his/her shoulders, provided the patient is correctly informed that there is no risk-free alternative.

Shifting the burden of responsibility sends us directly to the idea of autonomy, because the patient is seen as an autonomous person who has the right to decide on any medical procedure that may affect his/her health or endanger his/her life. In other words, informed consent is based on the fundamental premise that a patient or subject is a person possessing freedom of choice over their life or well-being. The choice is an autonomous action of the patient, who freely accepts a procedure involving risks. A doctor may obviously know a lot more than his/her patient in assessing a situation and applying a certain procedure, but that does not give him/ her the right to act against the patient's free choice. 
There is plenty of room for skeptical worries concerning the veracity and reality of this perspective. More often than not, a physician treats his/her patient not as an autonomous subject, but rather as a biological organism that needs "repairing", or as an individual who has no idea what is best for him. For instance, Katz severely criticizes doctors for encouraging patients to relinquish their autonomy. In his opinion, the most frequent situation is that of patient's manipulation and persuasion by the practitioners, and not that of keeping the relevant information from the patient with the purpose of obtaining the latter's informed consent: "the history of the physician-patient relationship from ancient times to the present (...) bears testimony to physicians' inattention to the right and need of their patients to make their own decisions. Little appreciation of disclosure and consent can be discerned in this history, except negatively, in the emphasis on the inability of patients to grasp the mysteries of medicine and therefore to share the burdens of decision with their doctors" (Katz 2002, 28).

But such doubts are not enough to put an end to a thorough analysis of the definition of informed consent, or even to make it look utopian. Let us suppose that we accept Katz's skepticism and his conclusion that in the real world, doctors ignore the principle of autonomy and patients' free choice. This does not imply that medical practitioners are necessarily bound to act this way and to ignore the patient's choices. They are free to act otherwise. For example, they could have the opposite attitude, taking into consideration the patient's choices, and this attitude would be something we would certainly want to enforce.

After all, from a more general point of view, the immorality of human behavior, which is, indeed, real, does not affect or erode the legitimacy of moral rules that all individuals should respect. On the contrary, the more immoral individuals are, the greater is the need to make them consider the governing moral rules as well as the measures required to overcome and reduce their immorality.

Now, going back to the principle of autonomy as an ethical foundation for informed consent, sometimes, this principle seems to be taken as being in opposition with the principle of beneficence concerning the doctor-patient relationship. For example, Faden and Beauchamp consider those principles as the ethical source for two different, even contradictory, types or models of doctor-patient relationship, which were competing for supremacy throughout the history of medicine.

In the model based on the principle of beneficence, one that could be derived from the Hippocratic Oath, the physician carries full responsibility for any medical procedure. The well-being of a patient prevails over his/her freedom of choice and, if need be, it allows the doctor to ignore the patient's decisions. The same principle says that no matter how well informed the patient may be, the final decision belongs to the doctor, given, of course, his/her medical expertise and knowledge.

On the other hand, in the model based on the principle of autonomy, which, according to Faden and Beauchamp, has emerged only in modern times, the fundamental idea is that the patient is the sole agent in charge of his/her fate. The 
doctor is not a completely autonomous decision-maker, but merely a person who carries out the patient's decision, a sort of delegated specialist acting in a framework set by the autonomous individual - the patient, whom he/she treats according to his/ her relevant expertise. Therefore, the principle of autonomy enforces the idea that "the autonomous person is not bound by controlling constraints and is in control of personal affairs” (Faden and Beauchamp 1986, 8).

Even though the tension between the two principles is intuitive and anyone could imagine scenarios in which those principles determine conflicting doctor-patient relations, this does not imply that we are somehow constrained to accept it. Although Faden and Beauchamp consider the opposition between these two principles as essential in any rational reconstruction of the history of medicine, quite a few critics have argued that these principles may collaborate rather harmoniously, based on a deeper presupposition seen as a cause or a foundation for both of them. More precisely, the opposition or the tension between the two principles can be real de facto, but hardly so de jure. Mazur, for example, argues that although those principles can outweigh each other in different stages of medical practice, this does not imply that they are necessarily at odds with each other. Moreover, "depending on the moral character of both practitioner and patient, they might be used in such a way as to complement each other" (Mazur 2012, 6). Though ambiguous ${ }^{3}$, this collaboration of the two principles according to the moral attitudes of practitioner and patient shows that the doctor's expertise is not always challenging (or in opposition with) the patient's choice. Therefore, we do not agree that the two principles determine, necessarily, opposing doctor-patient relationship patterns.

On the other hand, even if we do agree with the possibility of a harmonious collaboration between the two principles in medical practice, we should keep in mind the claim by Faden and Beauchamp that the principle of autonomy has started to gain ground only in modern times, more precisely a time when personal autonomy and freedom have become acknowledged as fundamental human rights, regardless of the context (or clinical situation). Hence, even if they could collaborate, the two principles might as well come to loggerheads, depending on the metaphysical presuppositions that lie deeper than the moral profile to which Mazur refers.

\footnotetext{
3 In order to avoid a wrongful misinterpretation of Mazur's opinion, we must stress that the ambiguity in question refers only to his discussion concerning the theory advanced by Faden and Beauchamp. In the ensuing chapters, the author elaborates on this idea and tries to explain how the moral profiles of both doctor and patient could support the collaboration between the two principles. However, we shall dwell longer on this subject in the last section.
} 


\subsection{Informed consent as an expression of morality}

The principle of autonomy is widely accepted as being an important foundation in the process of obtaining informed consent, but the principle's preeminence in clinical theory and practice is not considered a natural or necessary consequence, as someone could expect. Moreover, it could be argued that the principle of autonomy by itself is insufficient as a proper moral foundation for the practice of informed consent. For example, it could be argued that the unconditional respect for a patient's autonomy as a person could have immoral results or consequences. For instance, if a patient rejects a clinical intervention and the doctor accepts the patient's decision relying on the respect for the person's autonomy and free choice, the situation may endanger the patient's well-being and even life. In such a scenario, we may wonder whether accepting a person's autonomy is a moral gesture. Perhaps, we may need additional rules to avoid, as much as possible, putting a patient's life at risk.

In other words, placing the autonomy principle as an unconditional and sufficient basis for the morality of informed consent may turn the doctor-patient relationship into a sort of expert-client offer-and-acceptance transaction. Such an apparently objective type of relationship can imperil the patient's well-being, and even life ${ }^{4}$. Hence, the possible moral risks of the unconditional respect for the principle of autonomy need careful consideration.

One way to counter this objection is to declare that, in practice, the principle of autonomy should be backed up by the principle of beneficence, which helps a doctor supersede the patient's will and choose a certain clinical intervention when the patient's well-being and life are at stake. More precisely, the principle of autonomy should depend on the quality of the patient's choice and its degree of corroboration with the doctor's decision.

Though armed with relevant data provided by the doctor, a patient may decide against a clinical intervention that could improve his/her health and well-being, on the strength of the principle of autonomy. But the doctor could feel justified to take action and protect the patient's well-being, based on the principle of beneficence. In such a situation, the morality of the doctor's intervention would rely on the unconditional respect for the patient's well-being.

Moreover, to increase the legitimacy of the principle of beneficence, it could be argued that, in a therapeutic context, some of the individual's rights should be seen as being limited by his/her status as a patient, those rights being taken over by the doctor in his/her capacity as an expert. In other words, once a patient, the person tacitly admits to their inability to secure his/her well-being and life and cedes the right over his/her well-being and life to the physician. Leaving aside the idealism of

4 We say "apparently" because any expert-client transaction or relationship involves the two sides' subjective experiences and, more often than not, it is subjectivity that prompts their decisions. 
the tacitly assumed premise regarding the doctor's unconditional morality, such a strategy will not help us to avoid the objection mentioned above but only lead us to reformulate or transfer it to the other member of the doctor-patient relationship. If unconditional respect for the patient's autonomy could threaten the patient's wellbeing and life and, therefore, could trigger immoral consequences, then the same could be said about the unconditional respect for the patient's well-being, namely, the principle of beneficence.

Let us, for the sake of argument, suppose that the physician is an ideal moral agent who always bears in mind the Hippocratic Oath and all his/her actions are aimed at the patient's well-being. Even so, just like any human being, the doctor is a fallible cognitive agent who may be wrong in assessing a patient's situation and, therefore, prescribe a wrong treatment. It means that, despite his/her intention to do well, a doctor may put the patient at risk through his/her decisions. Moreover, if, ex hypothesi, the result is the only thing that matters to a patient, then the fact that this would be an unintentional error would not change the situation whatsoever. That is because it could be argued equally well that the patient's intentions when he/she rejects a certain intervention recommended by the doctor are just as good as those of the doctor. Moreover, it would be at least difficult, if not impossible, to legitimize the decision of the patient to give up his/her autonomy and free choice in a society based on inalienable individual rights and freedoms. In fact, such an attempt to justify the loss of a fundamental right for the alleged attainment of a greater good will most likely lead to totalitarian regimes.

Another strategy to counter the objection that unconditional respect for the autonomy principle may endanger the patient's well-being is to reinterpret or redefine the doctor-patient relationship. Mazur pleads for the Catholic Church's preeminence in approaching informed consent. Unlike secular doctrines, Mazur says, the Catholic Church promotes a partner-like relationship between doctors and patients. To this effect, he produces a series of Papal documents evincing a generous outlook on the informed consent protocol. For instance, the Charter for Healthcare Workers (Pontifical Council for Pastoral Assistance to Health Care Workers, Charter for Health Care Workers, Section II, Paragraphs 72-4) describes the relation between doctors and patients as one between equal partners whose subjective experience plays an important role, far better than an expert-client type of relation in which objectivity takes precedence. In other words, the Church sees doctors and patients teaming up to seek the patients' well-being. The same idea pertains to Ethical and Religious Directives for Catholic Health Care Services, where the doctor-patient relationship appears as "an important part of the foundation on which diagnosis and care are provided" (Ethical and Religious Directives for Catholic Health Care Services, 18), with an emphasis on the personal character of this relationship: "the Church's moral teaching on health care nurtures a truly interpersonal professional-patient relationship" (Ethical and Religious Directives, 19). Moreover, as equal partners, doctors and patients have equal, though distinct, responsibilities to preserve a person's well-being: "the person 
in need of health care depends on the skill of the health care provider to assist in preserving life and promoting health of body, mind, and spirit. The patient, in turn, has a responsibility to use these physical and mental resources in the service of moral and spiritual goals to the best of his or her ability" (Ethical and Religious Directives, 18-9).

According to Mazur, this personal type of relationship proves that the process of obtaining informed consent is a process of true personal development. Its main goal is not so much to adequately inform a patient and win his/her consent for a surgical intervention, as to build his/her moral conscience. This is actually Mazur's focal point in favoring the Catholic Church's informed consent doctrine. Though he fails to expand on the conscience formation process, Mazur points out that this element is entirely absent from the most important and significant secular documents on human rights and informed consent. Those declarations make no reference to or acknowledge "the need for formation of conscience" (Mazur 2012, 54).

Ambiguous as this doctrine of conscience formation may be, it certainly does not deal with moral conscience per se, but rather with its development in the specific situation of the doctor-patient relationship. In other words, the dialogue between the two partners over informed consent helps both of them to revise their equal moral duties toward a person in need of medical treatment, a process that may lead to a choice in agreement with their duties. Mazur seems to suggest that this equal responsibility toward a moral rule concerning both participants in the dialogue will naturally lead to a positive or, at least, a morally sound, decision. More precisely, this process could help us to avoid the undesirable effects potentially caused by unconditional respect for the principle of autonomy and, correspondingly, for the principle of beneficence. Keeping in mind the doctor's and patient's equally assumed task of preserving the life of any human being, we could say that the two partners are passing the responsibility for the decision and, implicitly, for the result of the clinical intervention, over to the moral rule under discussion. In other words, unconditional respect for the life of any human being turns both the doctor and the patient from decision/action agents into decision/action mediators.

The same interpretation of the relationship between doctor and patient as a partnership and a dialogical relationship determined by their common obligation to respect and protect the life of any human being can be found in the works of other authors, with different accents. Paul Ramsey, for instance, from a more robust Christian perspective, describes informed consent as a partnership based on the joint duty to preserve and protect the life of any human being. He considers informed consent as a joint doctor-patient experience (Ramsey 2002, 11), engaging both in a process of unraveling or, better said, enforcing the Ten Commandments in a medical environment. The doctor's and patient's common duty of care, seen as a sacred virtue sanctioned by the Bible, takes a specific hue in the case of informed consent, as an unconditional respect for the patient's well-being and life. 
Unlike Mazur, Ramsey says that the Bible, and not the Catholic Church, is the proper and absolute foundation for our duty to respect the life of any human being. However, the outcome is the same in both cases, because both the doctor and the patient must follow and obey a moral commandment lying beyond the principle of autonomy and the principle of beneficence (which require separate, individual moral duties). Together, they carry out or mediate the divine command.

Another point of view that favors a shared moral foundation that would bind doctor and patient together in the process of obtaining informed consent can be found in Edmund Pellegrino and David Thomasma's work. From a more-nuanced philosophical perspective, the two authors argue that medical practice in general - and informed consent in particular - should be grounded in some fundamental moral virtues that could enforce the morality of both doctor and patient. For example, in The Virtues in Medical Practice (Pellegrino and Thomasma 1993, 84), the authors argue that prudence or temperance is a fundamental medical virtue because it helps us take the best ethical decisions applied to each particular situation we come across, knowing that human well-being is the highest aim of any actions. Best ethical decisions are, naturally, those that may, by far, contribute to the patient's well-being. As long as both doctors and patients are educated in the spirit of these basic virtues or observe them unconditionally, the informed consent process is ethically safe.

In other words, similar to Mazur and Ramsey, Pellegrino and Thomasma are looking for a foundation much deeper than the autonomy principle, a foundation capable of making doctors and patients to respect and preserve life as equals. Such a foundation would make informed consent a truly and universally ethical endeavor.

\subsection{A moral dilemma and its philosophical presuppositions}

The two above-mentioned approaches seem to exclude each other because they build the informed consent process on different foundations and propose completely opposing guidelines. The first approach places the principle of autonomy at the core of the informed consent process, the patient being the sole decision-maker, while the doctor merely facilitates the patient's access to relevant data. In this perspective, informed consent is a mere medical application of the respect for individual liberty. Only the individual can truly decide what is good for him/her. Being a basic human right, it should be observed and respected even when a person's well-being depends on others, as when a person needs medical treatment. To put it in a nutshell, informed consent is seen as a particular expression of individual liberty and freedom of choice.

The other approach claims that the principle of autonomy is not sufficient as a moral foundation for informed consent, and that the principle of beneficence would actually offer a much more solid foundation for the doctor-patient relationship. Still, this perspective does not go to the full length of explicitly denying respect for the 
patient's autonomy and free choice ${ }^{5}$. However, by stressing that a patient should respect his/her own well-being unconditionally, it implicitly lessens the importance played by the autonomy principle. Therefore, an asymmetrical doctor-patient relationship, which according to the autonomy principle is an objective expert-client tie-up, is replaced by a symmetrical relationship, in which the two equal participants in the decision-making process are bound together by the ethical principle of unconditional respect for the well-being of the patient and, accordingly, for his/her life ${ }^{6}$.

At first glance, the antagonism seems to stem from an a priori preference for different moral values (freedom of choice versus well-being). If applied, this preference would give birth to divergent rules and procedures. In the case of the first perspective, unconditional respect for human well-being would depend on individual autonomy. For the second perspective, things would work the other way round, with respect for human well-being taking precedence over respect for the patient's autonomy. But such a description would be too straightforward and leave behind a natural and highly important question: why the preference for distinct values? All the more so as

5 That could be easily obtained by enforcing the beneficence principle as necessary and sufficient for medical practice. As a result, doctors would always and unconditionally have to act in favor of the patients' well-being, regardless of the latter's individual choices.

6 Someone might argue that the unconditional respect for human life is very different from the unconditional respect for the well-being of a patient and, accordingly, that they should not be taken together here. The first kind of respect is based on the principle that asserts, from a religious perspective, the sacredness of life (or, from a secular point of view, that life is an end in itself), whereas the second one is based on the principle of beneficence. But it is very difficult to see how a doctor could act according to the principle of beneficence (which means to act so as to always promote and sustain the patient's well-being) without respecting, at the same time (even if implicitly), the life of the patient as an end in itself or as being sacred. One usual reply to this is that, in the case of assisted suicide, the action of a doctor who puts an end to the patient's life (and, therefore, to his or her suffering) could be seen as morally legitimate according to the principle of beneficence, whereas, if the doctor would respect unconditionally the principle that asserts that life should be valued no matter what, he would not do this action. But how could this action be legitimate as an action that intends the well-being of a person? Well, the usual answer runs like this: by putting an end to suffering. The fact is, though, that after such an action, there would not be any patient/person who could benefit from that action. Assisted suicide is somehow a maximal or limit-case procedure, and it cannot be judged as we judge a surgical intervention to remove a damaged limb, for instance. In the second case, the patient will continue to exist and will be able to benefit from that action, whereas in the first case, this is obviously not true. So, we could say that the principle of beneficence could not be used, properly, to justify such an action, but rather the principle of autonomy. More precisely, the action of a doctor who acts according to the patient's will to suspend his or her life is legitimate in that it respects the right of the patient to decide over his or her own life, even if it may not be legitimate according to the principle of beneficence. If we accept this line of reasoning, we could say that it is rather natural and legitimate to associate the respect for the well-being of a patient with the respect for human life, and not vice versa. 
this preference manifests itself both at the level of foundations and also that of the rules and procedures guiding the process of obtaining informed consent.

For example, in the first perspective, a doctor may resort to arguments and appeal to the patient's reason in order to persuade him/her to accept a certain medical intervention. Unlike coercion, persuasion does not erode the respect for autonomy, because "persuasion is restricted to influence by appeal to reasons" (Faden and Beauchamp 1986, 261), which means that a medical doctor may plead for a certain intervention by presupposing that the patient is a reasonable-enough person to choose the best solution based on solid reasons.

In the second perspective, based on respect for the patient's well-being and life, the appeal to reason is replaced by an appeal to a common set of values, which should be observed unconditionally by the physician and his/her patient. This approach appears quite discernible in Mazur's analysis. While describing conscience formation as the main goal of the doctor-patient dialogue, Mazur takes a harsh stand against both human rights documents and secular theories on informed consent, criticizing their ignorance of ethical counseling. For instance, referring to human rights documents on informed consent, he notices that "none of these documents ever used the word 'conscience' except for the Declaration of Helsinki (...). Still, the Declaration never refers to the conscience of the patient, which is a substantial shortcoming” (Mazur 2012, 54). Later on, when discussing Beauchamp and Childress's theory, he concludes by saying that "although our authors allow for counselling in the informed-consent process, they understand it narrowly and do not provide satisfactorily for conscience or for its formation." (Mazur 2012, 71).

In the context of these considerations, we can introduce the following explanatory hypothesis: the answer to the above-mentioned question depends on the philosophical presuppositions that support the two perspectives on informed consent. The penchant for radically different values that characterize the two viewpoints is not a matter of free choice or, better said, it is not a preference, as we called it. It is rather a natural consequence that follows tacitly from two opposing worldviews and, in particular, from two opposing views on human nature.

In the first case, respecting the patient autonomy and founding the informed consent doctrine on the principle of autonomy emerge, naturally, from a secular vision of human nature. Individual freedom, including a person's freedom of choosing what to believe about himself/herself and his/her nature, is an innate, inalienable right. Individuals choose what is in their best interest to preserve their well-being and, in the specific framework of medical care, whether a medical intervention is acceptable. In short, only individuals have the right and freedom to decide what to do with their lives.

Correspondingly, in the second case, the respect for the patient's well-being and the justification of informed consent on the basis offered by the principle of 
beneficence stems, more often than not ${ }^{7}$, from a deeply religious worldview. Life is a gift given to man by God and unconditional respect for life is, therefore, the basic duty of every individual to God. That is why, in the context of the doctor-patient relationship and of the informed consent process, a God-fearing patient is bound to put his/her duty to respect life before his/her fundamental right to the freedom of choice. Moreover, given the fact that the patient's religious duty is also shared by his/her doctor, this gives rise to what could be called a symmetry of participation, leading to a subjective cooperation between doctor and patient or, as Mazur called it, the formation of moral conscience.

This hypothesis, according to which the values and, implicitly, the distinct principles on which informed consent is founded originate in different philosophical views, has at least two important consequences, one theoretical and the other, rather practical.

The first consequence is that the two perspectives on informed consent are irreconcilable and, perhaps more importantly, incommensurable. Since they stem from opposing philosophical presuppositions, any attempt at intertwining them or, as we have seen, criticizing them or pointing out their weaknesses against each other, is doomed to failure. Once the philosophical presuppositions behind them are made explicit, such debates become superfluous or simple rhetorical exercises. The reason can be easily detected: against the background offered by a secular metaphysical worldview, one according to which freedom is the best individual asset, the autonomy of conscience is a nonnegotiable, if not absolute, value; and vice versa, against the metaphysical background offered by a religious worldview, according to which human beings are essentially divine, the respect for human life becomes a decisive, nonnegotiable command.

In the first case, the necessity of (moral) conscience formation through the dialogue between the practitioner and the patient seems to be unjustified, if not extravagant. And that is because this secular worldview sees a person and his/her defining traits, including the formation of moral conscience, as a private matter, strictly reserved for individual autonomous introspection.

In the second case, if we assume the background offered by a religious worldview, the lack of such a process of moral counseling in the protocol of obtaining informed consent could seem, indeed, revolting ${ }^{8}$. That process could help the doctor and the patient to become aware of their moral duties or to revise them in the context of the divine command.

7 Although not necessarily, of course. Life could be seen as an end in itself on purely secular grounds, but the resulting effect would be the same, both the doctor and the patient would be bound to act so as to preserve and maintain life unconditionally.

8 As Mazur sometimes seems to be, alarmingly and repeatedly, pointing to this omission in the secular theories on informed consent, despite their own merits. 
The second consequence refers to medical practice, more exactly to the ethical uncertainties and traps that may affect the process of obtaining informed consent if we ignore the two antagonistic theories. As we have already seen, the two doctrines require an honest and truthful doctor-patient dialogue to help provide adequate information and lead to the patient's consent for the proposed medical treatment or clinical intervention. At first sight, this common trait could be neutral or constant, regardless of the above-mentioned theories. Informed consent will always involve communication, dialogue between doctors and patients. The content of that dialogue will always focus on a specific context the doctor and patient are in. But a deeper analysis will reveal that the dialogue and the direction where it heads depend, in their turn, on the metaphysical presuppositions of the informed consent doctrine assumed by the participants in that dialogue. To be more specific, a doctor may commit himself/herself to a process of rational persuasion or moral counseling of the patient, according to his/her own theory about informed consent. The patient may naturally react according to his/her own vision on this subject. We could easily imagine the confusion and disagreements that might appear and which could seriously undermine the doctor-patient relationship, be it a supposedly objective expert-client type relationship or a subjective fair-and-square equal partnership.

A dialogue that refuses to acknowledge and make explicit both sides' metaphysical presuppositions may never reach the consent stage or it may lead to imposing a particular moral ideology on the patient, disguised as a universal ethics. Both situations would eventually cripple the ethics of the whole process of informed consent and, sometimes, the patient's autonomy or well-being.

\subsection{Conclusions}

The solution to this theoretical and practical deadlock follows, somehow naturally, precisely from the moral dilemma mentioned above, and it already lies in the two doctrines discussed. If the ethics of the informed consent process depends on the worldviews of the two participants to the dialogue, then they should first of all go through a philosophical dialogue or counseling process to explain to each other and make explicit their personal metaphysical worldviews. This could take place in the presence of a counselor with philosophical expertise, who could act as an arbiter and could help the doctor and the patient to identify and properly formulate their particular views and the arguments on which they rest. Once this process of philosophical counseling is accomplished, the doctor and the patient may choose, together, the most suitable type of decision-making procedure in seeking genuine informed consent. At the end of this, nobody will be able to deny that consent was sought on a proper ethical background.

At first sight, our proposal may seem excessive, even extravagant. Why would physicians and researchers add one more stage to the process of seeking informed 
consent, thus delaying the patient's choice and the medical intervention? Although we cannot afford to reply to this objection at length here, it is worth noting that our proposal rests, implicitly, on the assumption that such a philosophical dialogue should be carried out only when time is not critical, and the life of the patient is not in imminent danger. In cases where there is simply not enough time, the discussion would be, of course, superfluous and inefficient. In such cases, even the protocol of obtaining informed consent would be disregarded, and the doctor would take a decision based solely on his/her medical expertise. But in cases where time is not a pressing factor, this preliminary philosophical dialogue between the doctor and the patient could play a critical role, considering the crucial importance of seeking informed consent. No measure can be disregarded as excessive or extravagant if we have time to use it to bring significant benefits or save a person's life (including here the person's right to have his/her own philosophical beliefs about human nature and the world). To uphold an opposed viewpoint would implicitly mean to disregard what is at stake, to shun the importance of seeking informed consent. Indeed, it would be difficult to sustain such a viewpoint on ethical grounds, and, accordingly, it would be unacceptable, particularly in the context of the subject tackled by this study.

\section{References}

Ethical and Religious Directives for Catholic Health Care Services, United States Conference of Catholic Bishops, 18. http://www.usccb.org/issues-and-action/human-life-and-dignity/ health-care/upload/Ethical-Religious-Directives-Catholic-Health-Care-Services-fifthedition-2009.pdf

Faden, Ruth F., and Tom L. Beauchamp. 1986. A History and Theory of Informed Consent. Oxford: Oxford University Press.

Katz, Jay. 1972. Experimentation with human beings. The Authority of the Investigator, Subject, Professions, and State in the Human Experimentation Process. New York: Russell Sage Foundation.

Katz, Jay. 2002. The Silent World of Doctor and Patient. Baltimore: John Hopkins University Press.

Mazur, Grzegorz. 2012. Informed Consent, Proxy Consent, and Catholic Bioethics. New York: Springer Science+Business Media B.V.

Pellegrino, Edmund, and David C. Thomasma. 1993. The Virtues in Medical Practice. Oxford: Oxford University Press.

Pernick, Martin S. 1982. “The Patient's Role in Medical Decision making: A Social History of Informed Consent in Medical Therapy", President's Commission for the Study of Ethical Problems in Medicine and Biomedical and Behavioral Research, Making Health Care Decisions. Washington, D.C., U.S.: Government Printing Office.

Pontifical Council for Pastoral Assistance to Health Care Workers, Charter for Health Care Workers, section II, paragraphs 72-74.http://www.ewtn.com/library/curia/pcpaheal.htm

Ramsey, Paul. 2002. The Patient as Person: Explorations in Medical Ethics. New Haven: Yale University Press. 